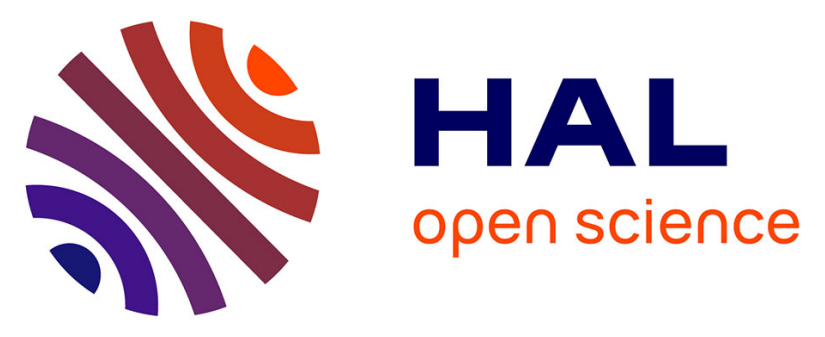

\title{
$\alpha$-Tocopherol Acetate Attenuates Mitochondrial Oxygen Consumption and Maintains Primitive Cells within Mesenchymal Stromal Cell Population
}

Darija Loncaric, Laura Rodriguez, Christelle Debeissat, Nicolas Touya, Veronique Labat, Arnaud Villacreces, Anne-Karine Bouzier-Sore, Jean-Max

Pasquet, Philippe Brunet de La Grange, Marija Vlaski-Lafarge, et al.

\section{To cite this version:}

Darija Loncaric, Laura Rodriguez, Christelle Debeissat, Nicolas Touya, Veronique Labat, et al.. $\alpha$ Tocopherol Acetate Attenuates Mitochondrial Oxygen Consumption and Maintains Primitive Cells within Mesenchymal Stromal Cell Population. Stem Cell Reviews and Reports, 2021, 17 (4), pp.13901405. 10.1007/s12015-020-10111-9 . hal-03376630

\section{HAL Id: hal-03376630 \\ https://hal.science/hal-03376630}

Submitted on 25 Oct 2021

HAL is a multi-disciplinary open access archive for the deposit and dissemination of scientific research documents, whether they are published or not. The documents may come from teaching and research institutions in France or abroad, or from public or private research centers.
L'archive ouverte pluridisciplinaire HAL, est destinée au dépôt et à la diffusion de documents scientifiques de niveau recherche, publiés ou non, émanant des établissements d'enseignement et de recherche français ou étrangers, des laboratoires publics ou privés. 
$\alpha$-Tocopherol acetate attenuates mitochondrial oxygen consumption and maintains primitive cells within mesenchymal stromal cell population.

Impact of $\alpha$-Tocopherol on MSC

Darija Loncaric $^{1,2,3}$, Laura Rodriguez ${ }^{1,2,3}$, Christelle Debeissat ${ }^{1,2,3}$, Nicolas Touya ${ }^{1,2,3}$, Veronique Labat 1,2,3 , Arnaud Villacreces ${ }^{2,3}$, Anne-Karine Bouzier-Sore ${ }^{4}$, Jean-Max Pasquet ${ }^{2,3}$, Philippe Brunet de la Grange $^{1,2,3}$, Marija Vlaski-Lafarge ${ }^{1,2,3}$ Sonja Pavlovic ${ }^{5}$ and Zoran Ivanovic ${ }^{1,2}$

${ }^{1}$ Etablissement Français du Sang Nouvelle Aquitaine, Bordeaux, France

${ }^{2}$ INSERM Bordeaux UMR 1035, Bordeaux, France

${ }^{3}$ Université de Bordeaux, Bordeaux, France

${ }^{4}$ Univ. Bordeaux, CNRS, CRMSB, UMR 5536, F-33000 Bordeaux, France

${ }^{5}$ Institute for Molecular Genetics and Genetic Engineering, University of Belgrade, Belgrade, Serbia

*Corresponding author

Zoran Ivanovic

zoran.ivanovic@efs.sante.fr

Place Amélie Raba Léon CS 2101033075 Bordeaux Cedex

Tel: 0556907550

Fax: 0556907551 
Abstract

We present here the data showing, in standard cultures exposed to atmospheric $\mathrm{O}_{2}$ concentration, that alpha-tocopherol acetate ( $\alpha$-TOA) has a positive impact on primitive cells inside mesenchymal stromal cell (MstroC) population, by maintaining their proliferative capacity. $\alpha$-TOA decreases the $\mathrm{O}_{2}$ consumption rate of MStroC probably by impacting respiratory chain complex II activity. This action, however, is not associated with a compensatory increase in glycolysis activity, in spite of the fact that the degradation of HIF-1 $\alpha$ was decreased in presence of $\alpha$-TOA. This is in line with a moderate enhancement of mtROS upon $\alpha$-TOA treatment. However, the absence of glycolysis stimulation implies the inactivity of HIF-1 $1 \alpha$ which might - if it were active - be related to the maintenance of stemness. It should be stressed that $\alpha$-TOA might act directly on the gene expression as well as the mtROS themselves, which remains to be elucidated.

Graphical Abstract

Alpha-tocopherol acetate $(\alpha-T O A)$, a synthetic vitamin E ester, attenuates electron flow through electron transport chain (ETC) which is probably associated with a moderate increase in mtROS in Mesenchymal Stromal Cells. $\alpha$-TOA action results in enhancement of the proliferative capacity and maintenance of the differentiation potential of the mesenchymal stem and progenitor cells.

Keywords

Alpha-tocopherol acetate, Electron transport chain, MStroC, MSC, MPC, mtROS, HIF-1 $\alpha$. 


\section{Introduction}

Mesenchymal Stromal Cells (MStroC), a population containing the Mesenchymal Stem and Progenitor cells (MSC and MPC) have the potential to be used in regenerative medicine $[1,2]$. MStroC are characterized by a prominent pro-survival/anti-apoptotic factors paracrine secretion, a capacity to modulate recipient immune response and an ability to home in on injured sites. These features, as well as the possibility to obtain them through all life span of the organism from various adult tissues including bone marrow (hBM MStroC), evoke firm interest for their use in cell therapy [1]. Perhaps the most attractive and challenging is potential MStroC application in recovery of ischemic tissue lesions, encompassing infarcted myocardium, ischemic limb injury, neural tissue after stroke etc. The main limitation for MStroC successful use is their poor post-transplantation retention and survival in ischemic tissue [3-5]. Experiments with MStroC low oxygen preconditioning (LOP), respecting physiological (in situ) oxygenation, have been pointed out as a potent strategy to improve their use in therapy [5]. However, variations in experimental conditions, applied oxygen concentration, duration or other cell culture parameters hurdle translation of the LOP to clinical use [6]. A significant complementary approach to LOP could be to propose and validate a clinical-grade agent that can conduct some of the major hypoxia-mimicking effects - electron transport chain (ETC)/ oxidative phosphorylation (OXPHOS) attenuation, mtROS signaling, metabolic shift toward glycolysis, or some Hypoxia Inducible Factors (HIF) [4]. Following our "metabolic hypothesis", propagation of MStroC under physiological oxygenation (low $\mathrm{O}_{2}$ values) might enhance properties of stemness (proliferative capacity and differentiation potential) mainly through induction of a metabolic shift toward glycolysis $[7,8]$. Therefore, introducing hypoxia-mimicking molecules during MStroC ex vivo expansion could be related to an additional benefit through favoring MSC and MPC pool. 
Among the synthetic compounds in use as pharmacological vitamin E supplement is an $\alpha$-tocopherol $(\alpha-\mathrm{TOH})$ ester, $\alpha$-tocopherol-acetate ( $\alpha$-TOA). The introduced acetate moiety at $-\mathrm{OH}$ group of chromanol ring augments molecule's stability, however it blocks its redox function. After administration in vivo, in the reaction of deesterification catalyzed by pancreatic esterase, antioxidative competent $\alpha-\mathrm{TOH}$ molecule would be re-established [9]. During the development of a solution for conservation of cells in hypothermia [10], we found that the ex vivo $\alpha$-TOA decreases the Oxygen Consumption Rate (OCR) of CD34+ cells, which was also confirmed in normothermic cultures [11]. This suggests that $\alpha$-TOA, already in clinical use, could be a highly attractive candidate for a hypoxia-mimicking molecule for hBM MStroC ex vivo expansion. In this study we are testing this hypothesis by evaluating the impact of $\alpha$-TOA on energetic metabolism and functional properties of hBM MStroC in a standard cell culture exposed to $20 \% \mathrm{O}_{2}$. The results we obtained revealed that $\alpha$-TOA not only efficiently decreases the OCR in hBM MStroC but also exhibits a positive effect on the maintenance of the proliferative capacity of MSC and MPC. This effect is probably related to the inhibition of the respiratory chain complex II, preventing an efficient electron flow. Curiously, this inhibition does not impact glycolysis rate, although accompanied with an enhanced stabilization of HIF-1 $\alpha$ that can be related to the moderate increase in mitochondrial ROS level upon $\alpha$-TOA treatment.

\section{Material and methods}

Isolation and preparation of hBM MStroC

hBM MStroC for this study were obtained from the mononucleated cell fraction from nine adult, healthy, human, bone marrow donors. Bone marrow cells were recovered from filters used for allogenic hematopoietic graft preparation. hBM MStroC were selected from bulk mononucleated bone marrow cell population by their property to adhere to plastic surfaces in standard cell culture conditions [12]. The RBS lysis was performed by $8.2 \mathrm{mg} / \mathrm{ml}$ ammonium chloride (Sigma - Aldrich, St 
Louis, MO), bone marrow cells were cultured in aMEM medium (Lonza \#BE12-169) supplemented with $10 \%$ v/v Fetal Bovine Serum (FBS, Hyclone GE Healthcare Life Science, \#SH30084.04), 1 ng/ml bFGF (Peprotech, \#100-18B-50UG), 1\% v/v Ultra Glutamine (Lonza, \#BE04-684E), 100U/ml penicillin/streptomycin 100U/ml/1000U/ml (CliniScience, \#03-031-5B) - cell culture medium, in 75 $\mathrm{cm}^{2}$ flask at $20 \% \mathrm{O} 2,5 \% \mathrm{CO} 2,95 \% \mathrm{H} 2 \mathrm{O}$ at $37^{\circ} \mathrm{C}$. After $3-4$ days, non-adherent cells were removed and cell culture medium was replaced by a fresh one. Selected adherent cells, mostly consisting of MStroC, were cultured for 14 days - up to reaching complete confluence. The obtained cellular material was tested to minimal criteria suggested by International Society for Cellular Therapy (ISCT) to be accepted as MStroC population. Upon discrimination, proper samples were cryopreserved for the future use in experiments as passage 0.

hBM MStroC expansion in $\alpha$-TOA-supplemented cell culture medium

To examine the effects of $\alpha$-TOA (Vitamine E Nepalm ${ }^{\circledR}$, Cenexi, Fontenay-sous Bois, France) on hBM MStroC, the cells were thawed (passage 0; see above), seeded at 5000 cells $/ \mathrm{cm}^{2}$ in four $75 \mathrm{~cm}^{2}$ separate flasks - one flask per each experimental condition and one control, in cell culture medium, and cultured for $24 \mathrm{~h}$ at $20 \% \mathrm{O}_{2}, 5 \% \mathrm{CO}_{2}, 95 \% \mathrm{H}_{2} \mathrm{O}$ at $37^{\circ} \mathrm{C}$ (Jouan SA, $\mathrm{CO}^{2}$ Incubator IGO150, France). Subsequently, the cultures were refilled by $10 \mu \mathrm{M}, 40 \mu \mathrm{M}$ or $150 \mu \mathrm{M}$ of $\alpha$-TOA-supplemented medium per flask and one flask was not treated, considered as a control. The cell cultures were propagated for next $72 \mathrm{~h}$ at standard conditions. The doses of $10 \mu \mathrm{M}$ and $40 \mu \mathrm{M}$ were chosen to represent the lowest and highest values of $\alpha \mathrm{TOH}$ plasma concentrations measured in human population $[13,14]$ as physiologically relevant, and the dose of $150 \mu \mathrm{M}$ as a supra-physiological one. Still, the serum concentration reasoning may not be totally applicable since the tissue $\alpha \mathrm{TOH}$ concentration seem to be lower with respect to the serum ones [15].

Impact of $\alpha$-TOA on hBM MStroC proliferation

To examine the impact of $\alpha$-TOA on proliferation kinetics of hBM MSroC, we seeded four sets of 25 $\mathrm{cm}^{2}$ flasks by $20 \times 10^{3}$ cells per flask. The one set was consisting of control group and $10 \mu \mathrm{M}-150 \mu \mathrm{M}-$ 
treated cells. Absolute cell numbers were counted using Trypan blue viability exclusion assay every day during the period of five days, starting with Day 2.

Evaluation of $\alpha$-TOA enrollment in hBM MStroC propagation through the cell cycle

To evaluate the possible role of $\alpha$-TOA in cell cycle modulation, treated and a control group of the cells were fixed, permeabilized and labelled by a combination anti-Ki67-Alexa 647 antibody (BD Biosciences, 561126) and intercalating agent propidium iodide (PI) (Invitrogen, Molecular Probes, \#PI 16063). The corresponding isotype antibody was used to eliminate possible non-specific immunoglobulin interactions. The cells were detached by trypsin (Lonza, \#CC-5012), washed and dispatched in the concentrations $10 \times 10^{6}$ cells $/ \mathrm{ml}$ for each experimental condition and a control for the following fixation step. The fixation was performed at ice-cold $0.5 \%$ formaldehyde (Sigma Aldrich, \#F8775) at $+4^{\circ} \mathrm{C}$ within $2 \mathrm{~h}$. The suspensions were washed and fixation was continued overnight in $80 \%$ ethanol (Sigma Aldrich, \# 34852-M) at $-20^{\circ} \mathrm{C}$. Fixed and washed cells were permeabilized by $0.25 \%$ Triton-X 100 solution (Sigma-Aldrich, \#9002-93-1) supplemented with $1 \%$ BSA (Sigma-Aldrich, \#A4737). Upon permeabilization, $10 \times 10^{4}$ cells from each condition and a control in volume of $100 \mu \mathrm{l}$ were labeled by a combination of $10 \mu \mathrm{l}$ anti-Ki67-Alexa647 and $10 \mu \mathrm{l} \mathrm{PI}$ for $1 \mathrm{~h}$ in the dark. The fluorescence was analyzed by flow cytometer BD FACS Canto II (Becton Dickinson, Rungis, France) using FACSDiva software (Becton Dickinson, Rungis, France).

Analysis of apoptosis rate

In short, after trypsinization the cells were rinsed by ice-cold PBS and resuspended in 1x binding buffer (Annexin V-FITC kit, Beckman Coulter, \#PN IM3546) at concentration of $10 \times 10^{6} \mathrm{cell} / \mathrm{ml}$. According to the manufacturer's instructions, in the volume of $100 \mu$ l of the prepared cell suspension, $1 \mu \mathrm{l}$ of Annexin V-FITC and $5 \mu \mathrm{l}$ of PI was added. The cells were vortexed gently and incubated for 15 minutes, on ice, in the dark. The incubation was ended by adding $400 \mu$ l of ice-cold 1x binding buffer. The fluorescence was analyzed immediately by flow cytometer BD FACS Canto II (Becton Dickinson, Rungis, France) using FACSDiva software (Becton Dickinson, Rungis, France). 
Functional characteristics of hBM MStroC treated by $\alpha-T O A$

a) Evaluation of the proliferative capacity of hBM MStroC traded by $\alpha$-TOA

Primary cultures

To examine the impact of $\alpha$-TOA on proliferative capacity of hBM MStroC we performed single-cell colony-forming assay. The $\alpha$-TOA treated cells $(10 \mu \mathrm{M}-150 \mu \mathrm{M})$ and control group of cells were trypsinized, PBS-rinsed and with limited dilution, concentration 0.3 cells $/ 100 \mu$ in non- $\alpha-T O A-$ supplemented cell culture medium were prepared. The single-cell dilutions were manually distributed into 96-well plates - one plate per experimental condition. Immediately after, by microscopic examination, only wells containing one, individual cell were considered as positive and recorded. The wells with no cell content or with more than one cell were excluded from the study. After 14 days of propagation in standard cell culture conditions, by microscopic examination, wells which contained colonies (CFU $-F$ ), raised from one single - individual cell, were counted as positive and the number of primary colonies was recorded.

\section{Secondary cultures}

To examine the capacity of $\alpha$-TOA treated cells to arise secondary colonies, we made limited dilutions 0,3 cells $/ 100 \mu \mathrm{l}$ in non- $\alpha$-TOA-supplemented cell culture medium from randomly chosen nine primary colonies for control, and each experimental condition - one dilution was made from the cells obtained from one primary colony, and in that manner for all primary colonies for three experimental and control conditions. Subsequently, each of the prepared dilutions was manually distributed onto a 96-well plate - one dilution per plate and wells containing only one cell - and the single-cell wells were discriminated by microscopic observation. After 14 days of propagation in standard cell culture conditions, the number of secondary colonies arisen from individual, single-cell obtained from primary colonies were counted. Alternatively, the whole cellular content of primary colony was analyzed in the secondary culture. This way, it is possible to directly evaluate the 
proportion of primary colonies able to generate the secondary colonies as well as calculate the proportion of initially plated single cells able to generate a secondary colony.

b) Evaluation of the differentiation potential of hBM MStroC traded by $\alpha$-TOA

The impact of $\alpha-T O A$ on hBM MStroC differentiation capacity was examined in the cells exposed to $10-150 \mu \mathrm{M}$ of the agent for $72 \mathrm{~h}$, and in a control, applying combined approach of single-cell colonyforming assays for evaluation of osteocytes, chondrocytes and adipocytes differentiation. Starting from an individual, single-cell, primary colonies were obtained in same manner as described for evaluation of $\alpha$-TOA-treated hBM MStroC proliferative capacity (see above). Subsequently, the content of one primary colony was split into 3 separate wells in the secondary 24-well plate cultures. The step was performed for each primary colony obtained in three experimental and a control condition. In each of three wells, seeded with cells originated from same primary colony, was initiated an osteocyte (StemPro Osteogenesis kit, \#A10072-01), or chondrocyte (StemPro Chondrogenesis kit, \#A10071-01) or adipocyte (StemPro Adipogenesis kit, \#A10070-01) differentiation process. In accordance to manufacturer's instructions to evaluate presence of chondrocytes, osteocytes and adipocytes respectively, after 14 days of propagation in culture, the cells which were exposed to chondrocyte differentiation conditions, were strained by Alizarin Blue (Sigma, \#A3157-10G), wells which were exposed to adipocyte differentiation were strained by combination Red Oil (Sigma, \#01391) and Hematoxylin (Sigma, \#Mx69708049) and finally after 21 days, cells which were undergoing osteocyte differentiation conditions were stained by Alizarin Red (Sigma, \#A5533-25G). The assay performed in this manner allowed us to examine the impact of $\alpha$ TOA on individual - single-cell tri -, bi -, uni- or non- linage differentiation potential.

Bioenergetic parameters evaluation in hBM MStroC treated by $\alpha$-TOA

Activity of mitochondria 
The oxygen consumption rate (OCR), as a parameter of mitochondrial activity, was determined in hBM MStroC exposed to $10 \mu \mathrm{M}-150 \mu \mathrm{M}$ of $\alpha$-TOA for $24 \mathrm{~h}$ and in a control group, by using XF 24 Flux analyzer (SeaHorse Bioscience XF 24, Instruments, North Billerica, MA). The method applied for OCR evaluation is described in detail in: [16]. Briefly, thawed passage 0 hBM MStroC were seeded at $2 \times 10^{4}$ cells per well in a XF 24 cell culture plate (SeaHorse Bioscience, part\# $100777-004$ ) in cell culture medium and incubated for $72 \mathrm{~h}$ at $20 \% \mathrm{O}_{2}, 5 \% \mathrm{CO}_{2}, 95 \% \mathrm{H}_{2} \mathrm{O}$ (Jouan SA, $\mathrm{CO}_{2}$ Incubator IGO150, France). The cell culture medium was supplemented by $0 \mu \mathrm{M}, 10 \mu \mathrm{M}, 40 \mu \mathrm{M}, 150 \mu \mathrm{M}$ of $\alpha-\mathrm{TOA}$ and incubation was continued in standard cell culture conditions for the next $24 \mathrm{~h}$. On the day of OCR evaluation, the medium was replaced by XF Base Medium (part\# 102353-100) that was pre warmed at $37^{\circ} \mathrm{C}, \mathrm{pH}$ adjusted at 7.4 and supplemented by $100 \mathrm{mM}$ pyruvate (Sigma Aldrich, \#P8574), 200g/l glucose (Sigma Aldrich, \#G8270) pH 7,4, 200mM ultra-glutamine (Lonza, \#BE04684E,), 1000x penicillin streptomycin mix (Clinisciences, \#03-031-5B). Before the OCR values evaluation, the cells were incubated for $1 \mathrm{~h}$ at atmosphere with no $\mathrm{CO}_{2}$ at $37^{\circ} \mathrm{C}, 20 \% \mathrm{O}_{2}$ (Jouan $\mathrm{SA}$, EB115 ELEC SN CAB, France). The OCR was detected before and after subsequent injection of each modulatory compound: modulator 1: 1,27 $\mu \mathrm{M}$ oligomycin (Sigma Aldrich, \#75351), an inhibitor of F0

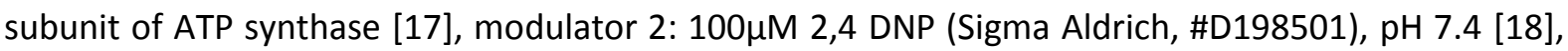
decoupling agent and a modulator 3: mixture of $1 \mu \mathrm{M}$ rotenone (Sigma Aldrich, \#R8875,) and $1 \mu \mathrm{M}$ antimycin (Sigma Aldrich, \#A8674), inhibitors of complex I [19] and complex III of ETC [20] respectively. In order to normalize detected OCR values per total cell number per well, at the end of each experiment "average cell number" was counted in minimum 4 wells per experimental condition by using Trypan Blue (Gibco, \#15250061,) viability exclusion assay. The OCR values were expressed in $\mathrm{pmol} / \mathrm{min} / 50000$ cells. These values were used to determine parameters of mitochondrial activity according to the instructions: https://www.agilent.com/cs/library/usermanuals/public/XF_Cell_Mito_Stress_Test_Kit_User_Guide. pdf. 
$\alpha-T O A$

In three distinct series of experiments the activities of complex I, II and IV of ETC were evaluated in permeabilized hBM MStroC previously treated with 10-150 $\mu \mathrm{M}$ of $\alpha$-TOA for $24 \mathrm{~h}$ (or not treated) by determining OCR with XF 24 flux analyzer (SeaHorse Bioscience XF 24, Instruments, North, Billerica, MA). The applied method and experimental procedures used to evaluate the activity of each analyzed ETC complex is reviewed in detail by Salabei et al. [21].. The thawed passage 0 hBM MStroC were plated at concentration $2 \times 10^{4}$ cells/well in a XF 24 cell culture plate according to manufacturer's instructions (SeaHorse Bioscience, part\# 100777 - 004). The incubation proceeded for $72 \mathrm{~h}$ in water-saturated atmosphere $\left(20 \% \mathrm{O}_{2}\right)$ with $5 \% \mathrm{CO}_{2}$ at $37^{\circ} \mathrm{C}$. Upon 3 days, cell culture medium was replaced by the medium supplemented with $0 \mu \mathrm{M}$-control and $10 \mu \mathrm{M}, 40 \mu \mathrm{M}$ or $150 \mu \mathrm{M}$ - experimental conditions and incubation was continued for the next $24 \mathrm{~h}$ under standard cell culture conditions. On the day of the experiment, the cells were rinsed and incubation medium was replaced by fresh home-made mannitol and saccarose buffer (MAS) containing 70mM sucrose (Calbiochim, \#573113), 220mM mannitol (Alfa Aesar, \#A14030) 10mM KH2PO4 (Calbiochim, \#529568) 5mM MgCl2 (Sigma, \#M8266), 2mM HEPES (Alfa Aesar, \#A14777,) and 1mM EGTA( Sigma,\#E4378), pre-warmed at $37^{\circ} \mathrm{C}, \mathrm{pH}$ adjusted at 7.2 by $0.1 \mathrm{M} \mathrm{KOH}$. Before OCR measuring by 24 XF flux analyzer, the plates were exposed for 10 minutes to atmosphere with no $\mathrm{CO}_{2}$ at $37^{\circ} \mathrm{C}$ and $20 \% \mathrm{O}_{2}$.

To assess activity of complex I, the OCR was determined before injection of any modulatory compound - a basal OCR (BOCR), after addition of the mixture $-25 \mu \mathrm{g} / \mathrm{ml}$ digitonin (Sigma Aldrich, \# D141)/ 1mM ADP (Sigma Aldrich, \#A5285)/ 1mM pyruvate (Sigma Aldrich, \#P8574)/ 2mM malate

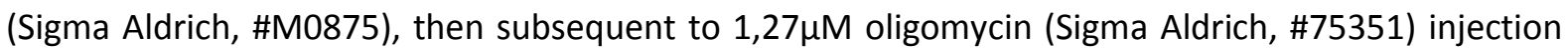
and after $10 \mu \mathrm{M}$ of rotenone (Sigma Aldrich, \#R8875) addition. The evaluation of complex II activity enrolled first BOCR measurement, OCR determination upon $25 \mu \mathrm{g} / \mathrm{ml}$ digitonin (Sigma Aldrich,

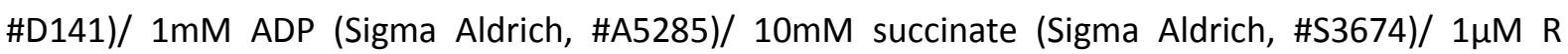




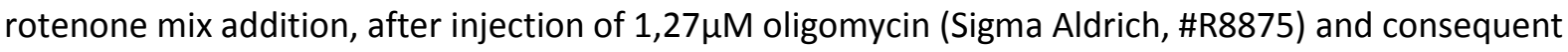
to complete the ETC shut-down by $10 \mu \mathrm{M}$ of antimycin (Sigma Aldrich, \#A8674) addition. The complex IV activity measuring encompassed the same initial BOCR detection, followed by OCR determination upon mix - $25 \mu \mathrm{g} / \mathrm{ml}$ digitonin (Sigma Aldrich, \#D141)/ 1mM ADP (Sigma Aldrich,

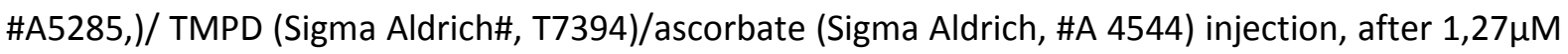
oligomycin (Sigma Aldrich, \#75351) addition and subsequent to Azide K (Sigma Aldrich, \#740411) injection, a direct inhibitor of complex IV. The obtained OCR values were expressed in 200000 cells per $\mathrm{pM} /$ minute. These values were used for each individual complex to estimate state III and IV of respiration and respiration control ratio $(\mathrm{RCR})[21]$.

Glycolytic activity

a) Parameters of Glycolytic Flux determined by SeaHorse

The extracellular acidification rate (ECAR) as an indicator of glycolytic activity, was determined by XF 24 Flux analyzer (SeaHorse Bioscience XF 24, Instruments, North Billerica, MA) in the hBM MStroC treated with $10-150 \mu \mathrm{M} \alpha-$ TOA for $24 \mathrm{~h}$ and in a control (method reviewed in details by Qiam et all). The hBM MStroC were seeded and exposed to $\alpha-T O A$ in the same manner as described in section Material and Methods, Activity of mitochondria (see above). On the day of ECAR measuring, the cell culture medium was replaced by XF Base medium (part\# 102353-100) that was pre-warmed at $37^{\circ} \mathrm{C}$, $\mathrm{pH}$ adjusted at 7.4 and supplemented by $1000 x$ penicillin streptomycin mixture concentration $1 \mu \mathrm{l} / \mathrm{ml}$ (Clinicians, \#03-031-5B). Subsequently, the cells were incubated for $1 \mathrm{~h}$ at atmosphere with no $\mathrm{CO}_{2}$ at $37^{\circ} \mathrm{C}, 20 \% \mathrm{O}_{2}$ (Jouan SA, EB115 ELEC SN CAB, France). The ECAR was measured prior to and after successive injections of the modulatory compounds: modulator 1-2g/l glucose (G8270, \#Sigma

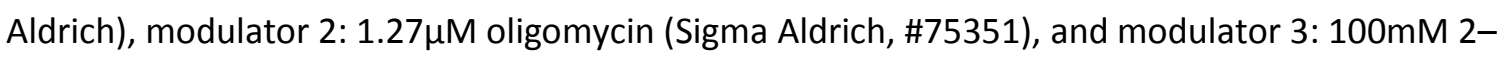
deoxy glucose, $\mathrm{pH} 7.4$ (Sigma Aldrich D6134). At the end of measuring, the "average cell number" in at minimum 4 wells per condition was counted by Trypan blue exclusion assay. The ECAR values were expressed in $\mathrm{mpH} / \mathrm{min} / 50000$ cells, those values were used to calculate glycolytic flux 
parameters according to the instructions:

https://www.agilent.com/cs/library/usermanuals/public/XF_Glycolysis_Stress_Test_Kit_User_Guide. pdf.

b) Measurement of lactate production

At the end of a $24 \mathrm{~h} \alpha-$ TOA treatment, the cells were exposed to [1-13C] Glucose for 4 hours. Perchloric acid extract of cellular samples and media were analyzed by $1 \mathrm{H}$ HRMAS spectroscopy on a Bruker DPX $500 \mathrm{MHz}$ magnet. ${ }^{1} \mathrm{H}-\mathrm{NMR}$ spectra were acquired with a $90^{\circ}$ pulse angle (adjusted for each sample), relaxation time of $8 \mathrm{~s}$, relaxation delay of $8 \mathrm{~s}$, spectrum width of 10 parts per million $(\mathrm{ppm})$, acquisition time of $3.28 \mathrm{~s}, 128$ scans and $32 \mathrm{~K}$ memory size. The water signal was suppressed by homonuclear prestarvation. From these spectra, the $\left[3-{ }^{13} \mathrm{C}\right]$ lactate production was measured, indicating the glycolytic level in the cells. The specific enrichment $\left(\%\right.$ of $\left.{ }^{13} \mathrm{C}\right)$ of lactate carbon 3 was determined from the ratio of the integral of the lactate satellite peaks resulting from heteronuclear spin-coupling to the sum of the integrals of satellite and central peaks. Perchloric acid extract spectra were normalized thanks to ethylene glycol and protein contents.

Measurement of mitochondrial ROS levels

The level of mtROS were quantified by using fluorescent probe MitoSOX (Invitrogen by Termo Fisher Scientific, M366008) in hBM MStroC treated by $\alpha-T O A$ for $24 \mathrm{~h}$ and in control condition. After trypsinization, the cells were rinsed by pre-warmed cell culture medium at $37^{\circ} \mathrm{C}$. To measure ROS produced by mitochondria, the cells were resuspended at HBSS (Thermo Fisher Scientific $\# 14025092$ ) in concentration $10 \times 10^{5}$ cells $/ \mathrm{ml}, 5 \mu \mathrm{M}$ of fluorescent probe MitoSOX was added and cells were incubated for 15 minutes in the dark at $37^{\circ} \mathrm{C}$. After completed incubations, the cells were rinsed by pre-warmed at $37^{\circ} \mathrm{C}$ PBS (Lonza, \#17-516F). Intracellular fluorescence was detected by flow cytometer BD FACS Canto II (Becton Dickinson, Rungis, France) using FACSDiva software (Becton Dickinson, Rungis, France). 
Estimation of mitochondrial inner membrane potential and mitochondrial mass

Mitochondrial inner membrane potential and mitochondrial mass were measured in hBM MStroC exposed to $20 \% \mathrm{O}_{2}, 3 \% \mathrm{O}_{2}$, - control conditions and in hBM MStroC exposed to $10 \mu \mathrm{M}$ of $\alpha$-TOA for $24 \mathrm{~h}$. To estimate mitochondrial inner membrane potential $2 \times 10^{5}$ cells per condition were incubated with 20nM Tetramethylrhodamine Methyl Ester Perchlorate (TMRM) (Thermo Fisher Scientifics, \#T668) for 30 minutes in the dark at $37^{\circ} \mathrm{C}$. The cells were rinsed and florescence detected by BD FACS Canto II (Becton Dickinson, Rungis, France) and FACSDiva software (Becton Dickinson, Rungis, France). Subsequently in each tube $100 \mu \mathrm{M}$ of 2,4 DNP was added and incubated for 10 minutes in the dark at $37^{\circ} \mathrm{C}$. The samples were rinsed and new level of fluorescence estimated. The mitochondrial inner membrane potential was obtained for each sample a as difference in detected fluorescence before and subsequently to 2,4 DNP addition. The mitochondrial mass was detected by incubation of $2 \times 10^{5}$ cells per condition with Mito Tracker Green florescent probe (MTG) (Thermo Fisher Scientifics, \#M7514) for 30 minutes in the dark at $37^{\circ} \mathrm{C}$. The cells were rinsed and florescence level estimated by BD FACS Canto II (Becton Dickinson, Rungis, France) and FACSDiva software (Becton Dickinson, Rungis, France).

Detection of HIF-1 $\alpha$ protein subunit by Western Blot

The protein extracts obtained from hBM MStroC exposed to $0-150 \mu \mathrm{M}$ of $\alpha$-TOA for $72 \mathrm{~h}$ at $20 \% \mathrm{O}_{2}$ were subjects of Western Blot analyzes for HIF-1 $\alpha$ protein expression. In the experiment, control conditions were: 1 ) the protein extracts of hBM MStroC expanded at $20 \% \mathrm{O}_{2}$ during $24 \mathrm{~h}$ or $72 \mathrm{~h}$, used as negative controls; 2 ) the extracts obtained from $\mathrm{hBM} M S t r o C$ expanded for $24 \mathrm{~h}$ or $72 \mathrm{~h}$ at $3 \% \mathrm{O}_{2}$ and 3) the proteins extracted from $\mathrm{hBM}$ MStroC expanded at $20 \%$ and $3 \% \mathrm{O}_{2}$ in duration of $24 \mathrm{~h}$ and $72 \mathrm{~h}$ with added $100 \mu \mathrm{M} \mathrm{CoCl}_{2}$ in the last $6 \mathrm{~h}$ of incubation, used as positive controls. The protein extraction from the cells incubated at physiologically relevant oxygen concentration were performed in a $\mathrm{O}_{2}$ and $\mathrm{CO}_{2}$ concentrations controlled working station BioSpherics (\# X Vivo) in the work atmosphere with $1 \% \mathrm{O}_{2}$, whereas from the samples incubated at $20 \% \mathrm{O}_{2}$ proteins were extracted in 
standard sterile-cell-culture-condition at atmospheric oxygen concentration. The same steps to induce cell lysis and obtain protein extracts were performed. The trypsinization was done by $25 \%$ (w/v) Trypsin - EDTA (Lonza, \#CC-5012) and the total number of hBM MStroC was evaluated by Trypan Blue viability exclusion assay. Chemical cell lysis was performed by homemade sample lysis buffer.

Western Blot analyzes were performed on total protein extract obtained from $2.5 \times 10^{5}$ cells. The protein extracts were separated according to molecular weight on homemade $8 \%$ SDS-PAGE gel by using BioRad vertical electrophoresis system and power at $100 \mathrm{~V}$ for 90 minutes. The separated proteins were transferred on PVDF membrane (BioRad, \#1620177) membrane which was power supplied by Trans Blot Turbo transfer system (\#10026938) $25 \mathrm{~V}, 0.7 \mathrm{~mA}$, duration 30 minutes. The membranes were blocked by Tris buffer saline $0.1 \%$ Tween 20 (TBS - T) supplemented by $5 \%$ fat, dried milk, for $1 \mathrm{~h}$ incubation at room temperature. After saturation, membranes were incubated with 1:1000 HIF -1 $\alpha$ (Abcam, \#ab51608) or with 1: $5000 \beta$-actin (Sigma - Aldrich, \#A2066) primary antibody overnight, at $+4^{\circ} \mathrm{C}$. The blots were washed 3 times with $1 \mathrm{x}$ TBST at room temperature. Subsequently they were incubated with horseradish peroxidase-conjugated rabbit specific secondary antibody, for $1 \mathrm{~h}$, at room temperature. After incubation with a secondary antibody, the membranes were washed 3 times. The immunoreactive proteins were detected by using BioRad Western Blot revelation Western ECL Substrate (BioRad, \#102031035) and Clarity Western ECL, Substrate (BioRad, \#102031033). Studio image 3.1 Software was used for band intensity quantification.

Testing Vitamin E relevance for in vivo mesenchymal stem and progenitor cell maintenance

The 3-week old C57Black mice were divided into 3 groups, with ten mice each: 1) mice receiving Vitamin E-free food (custom food U8959, Safe nutrition, Augy, France) (“Deficiency" group); 2) mice receiving the same U859 food supplemented with $40 \mathrm{mg} / \mathrm{kg}$ of $\alpha$-TOA ("Control" group) and 3) mice receiving Vitamin E-free U8959 food for 2 months and then the same food supplemented with 
$40 \mathrm{mg} / \mathrm{kg}$ of $\alpha$-TOA for additional 3 months ("Deficiency resolved group"). After 2 and 5 months vitamin E levels were determined in the mouse serum (see details in Supplementary Methods). After 5 months the mice were sacrificed and the number of CFU-F (enabling insight into the mesenchymal stem and progenitor cell compartment) was determined in their femoral bone marrow (see details in Supplementary Methods).

Statistical analyses

Concerning the energetic metabolism experiments, numerical data for each set of experiments and each analyzed group were expressed as average value with \pm standard deviation (SD). Differences in measured OCR or ECAR rates between control and $\alpha$-TOA treated hBM MStroC were tested by nonparametric Mann-Whitney $U$ test. The performed tests were two-tailed and $p$-values less than 0,05 were indicated as significant differences. Statistical analyzes were performed using GraphPad Prism software version 6,01 (La Jolla, California, USA). Concerning the mtROS determination, the results were expressed in percentage with respect to the control $\left(0 \mu \mathrm{M} \alpha-\mathrm{TOA}, 20 \% \mathrm{O}_{2}\right)$. The significance of differences was tested by the non-parametric Mann-Whitney $U$ test.

\section{Results}

$\alpha$-TOA does not interfere with the proliferation kinetics of hBM MStroC

During a 7-day culture, the kinetics of proliferation of hBM MStroC with the 3 doses of $\alpha$-TOA was comparable to those in the control cultures (w/o $\alpha$-TOA) (Figure 1A).

As judged on the basis of the $72 \mathrm{~h}$ expansion at $\alpha$-TOA supplemented medium, the cell cycle progression was also identical in the cultures w/o and with 3 doses of $\alpha$-TOA tested (Figure 1. B).

$\alpha$-TOA provokes neither apoptotic nor necrotic death of hBM MStroC. Combined annexin V (AnnV)/ propidium iodide $(\mathrm{PI})$ staining is presented, the flow-cytometry plots are from a representative 
experiment out of three (Figure 2A). The quantitative analysis of different categories of MStroC with respect to the AnnV and PI staining on the basis of three independent experiments (Figure 2B) does not reveal an effect of $\alpha$-TOA on cell death. More than $80 \%$ of hBM MStroC are viable and apoptosis free.

$\alpha$-TOA enhances the proportion of progenitors with high proliferative capacity in a standard ex vivo culture exposed to $20 \% \mathrm{O}_{2}$ concentration.

After 14 days of culture without $\alpha$-TOA, single-cell cultures revealed that $~ 60 \%$ hBM MStroC of firstpassage exhibit a CFU-F activity i.e. were able to form primary colonies (Figure 2A). The presence of $\alpha$-TOA, starting from the lowest dose $(10 \mu \mathrm{M})$ resulted in increase of colony-forming efficiency: almost the totality of hBM MStroC $(<90 \%)$ acquired the colony-forming ability. When the total cell content of a colony was replated into a secondary culture (see scheme), $\sim 20 \%$ of primary colonies produced the secondary colonies (Figure 2B). This percentage is tripled if the $\alpha$-TOA was present in the initial culture ( $65 \%)$, although the amplitude of the effect seems to decrease with the dose, since $150 \mu \mathrm{M}$ of $\alpha-$ TOA ensures the doubling $(\sim 45 \%)$ in the percentage of primary colonies producing the secondary ones. These results suggest that $\alpha$-TOA enhances the number of primitive stromal progenitor/stem cells i.e. that it "pushes", in course of asymmetric divisions, the balance of selfrenewal and commitment towards self-renewal. Taking into account the real number of hBM MStroC at the end of a $72 \mathrm{~h}$ period in different conditions, the number of the cells able to give the colonies in secondary cultures was calculated (not shown). This allows to present a relative amplification index for these cell subpopulations in respect to the control condition (w/o $\alpha$-TOA): as it can be seen (Figure $2 \mathrm{C}$ ), the numeric expansion of primitive high proliferative capacity cells able to maintain the clone in secondary culture is $4.5,3.4$ and 2.8 folds higher in cultures supplemented by $10 \mu \mathrm{M}, 40 \mu \mathrm{M}$ and $150 \mu \mathrm{M}$ of $\alpha-\mathrm{TOA}$, respectively. Replating the individual cells from a primary colony in single-cell cultures (see scheme) revealed that $\alpha$-TOA does not largely impact the proportion of cells that produced the secondary colonies, although a trend of an increase in this proportion exists 
with the lowest dose of $\alpha-\operatorname{TOA}(10 \mu \mathrm{M})$ (Figure 2D). This result suggests that $\alpha$-TOA does not alter the individual proliferative capacity of high proliferative potential stromal progenitors/stem cells. When the cell content of a colony from primary culture is recovered and split up into 3 secondary culture wells, each pushing towards one differentiation way (osteo-, chondro-or adipogenic), it is possible to evaluate the proliferative potential of the cell which is in origin of the colony in primary culture. If the single-cell clone yields all three types of cell, the stem/progenitor cell was multipotent (tripotent), if two types - bipotent, one only - unipotent (Figure 2E). This approach showed that $\alpha$ TOA in the dose of $10 \mu \mathrm{M}$, which has the most prominent effect on the maintenance of the proliferative capacity, does not influence the commitment/differentiation of mesenchymal stem/progenitor cells (Figure 2). However, the doses of 40 and $150 \mu \mathrm{M}$ produced a relatively higher percentage of bipotent progenitors ( $50 \%$ vs. $\sim 35 \%$ ) at the expense of multipotent ones (decrease from $\sim 55 \%$ to $\sim 40 \%$ ) (Figure $2 \mathrm{E}$ ). A numerical expansion of primitive cells with a high proliferative capacity, able to maintain the clone in secondary culture is $4.5,3.4$ and 2.8 fold higher in cultures supplemented by $10 \mu \mathrm{M}, 40 \mu \mathrm{M}$ and $150 \mu \mathrm{M}$ of $\alpha$-TOA respectively (Figure $2 \mathrm{D}$ ), than in the control culture without the $\alpha$-TOA. In fact, an increased frequency of secondary culture colony-forming cells for 10,40 and $150 \mu \mathrm{M}$ with respect to the control culture (Figure $2 \mathrm{~B})$ ), combined with $~ 15 \%$ more primary colonies (Figure 2A) and associated with a similar expansion fold of MStroC in all conditions (Figure 2A) maintains the numeric expansion. Thus, even in the conditions of $40 \mu \mathrm{M}$ and $150 \mu \mathrm{M}$ of $\alpha-T O A$, the decrease in the proportion of multipotent cells cannot counteract their numerical amplification of multipotent cells since determination of both categories is dependent on the capacity of the secondary culture colony formation. Thus, taking into account the numerical expansion, even the highest dose of $\alpha-T O A$ amplifies better both multipotent and bipotent progenitors than the culture without $\alpha$-TOA.

$\alpha$-TOA interferes with mitochondrial activity in hBM MstroC by decreasing the $\mathrm{O}_{2}$ consumption rate 
The parameters of mitochondrial activity (basal rate of cellular respiration, mitochondrial oxygen consumption, non-mitochondrial consumption, the maximal respiratory capacity, spare capacity and proton leak) in hBM MStroC treated by $10 \mu \mathrm{M}, 40 \mu \mathrm{M}, 150 \mu \mathrm{M}$ and in control group (w/o $\alpha \mathrm{TOA}$ ) were determined (Figure 3A). A statistically significant decrease in basal oxygen consumption rate by hBM MStroC was detected in presence of $\alpha$-TOA: $1.77 ; 2.27 ; 5.11$ folds for doses of $10 \mu \mathrm{M}, 40 \mu \mathrm{M}$ and $150 \mu \mathrm{M}$, respectively, vs non-treated cells (Figure $3 \mathrm{~A}, \mathrm{~B}$ ). The decrease in calculated values of mitochondrial oxygen consumption rate in hBM MStroC, compared to the control condition, were also dose-dependent (3.23; 4.57 and 7,32-fold for $10 \mu \mathrm{M}, 40 \mu \mathrm{M}$ and $150 \mu \mathrm{M}$, respectively) (Figure 3C). $\alpha$-TOA did not impact the non-mitochondrial oxygen consumption of hBM MStroC, although the highest dose of $\alpha$-TOA tested $(150 \mu \mathrm{M})$ decreased more than twice non-mitochondrial $\mathrm{O}_{2}$ consumption, which was, however, not statistically significant (Figure 3D). Compared to non-treated (control) cells, the maximal respiratory capacity was decreased: $15.3 ; 3.8 ; 4.5$-fold in respect to applied dose $(p<0.05)$ (Figure 3E). This finding is important since it points to an inhibition by $\alpha$-TOA of at least one of the respiratory chain complexes rather than an ATP-synthase-related event. Furthermore, hBM MStroC exposed to $\alpha$-TOA showed lower capacity to respire close to the theoretical maximum when compared to non-treated cells (Figure 3F). No significant change in the "proton leak" parameter, obtained as a difference in OCR between the situations when the respiratory chain is shut down by the blockage of the complexes I and III and the situation where the ATP-synthase is blocked, was detected in experimental vs. control group (Figure 3G), indicating no mitochondrial destabilization.

a-TOA inhibits complex II activity

As already pointed out, the results concerning the maximal respiratory capacity (Figure $3 \mathrm{E}$ ) are indicative of the perturbations by $\alpha$-TOA of at least one of the respiratory chain complexes. To elucidate this point, we studied the effect of $\alpha$-TOA on the complexes one by one, except the complex III (technical issues) (Figure 4). As measured in the situation of maximal ATP production 
("State III"), the only significant changes were at the level of complex II whose activity was decreased (Figure 4D). However, a similar trend is visible at the level of complex IV (Figure 4G). In the situation of a low energy demand (high ATP:ADP level) ("State IV"), a significant inhibition of the complex II activity persisted (Figure 4E), while the trend of inhibition disappeared at the complex IV level (Figure 4H). Thus, the only consistent phenomenon is the complex II inhibition by $\alpha$-TOA (Figure 4).

$\alpha$-TOA does not interfere with the glycolytic rate

Neither basal extracellular acidification rate (BEAR) (Figure 5A,B) nor glycolitic activity measured after glucose injection in culture (Figure $5 \mathrm{~A}, \mathrm{C}$ ) was significantly changed in presence of $\alpha$-TOA. Note that the blockage of ATP synthase (Glycolytic Capacity, (Figure 5D) and Glycolitic Reserve (Figure 5E)) does induce only a mild compensatory enhancement of ECAR (very slight intensification of glycolysis, (Figure 5A and Figure 5E) in non-treated MStroC as well as in the $\alpha$-TOA treated ones. Thus, no compensatory enhancement of the glycolysis is detected in response to the attenuation of the electron flux in mitochondrial respiratory chain by $\alpha$-TOA (Figure 3 ). This is in line with the results of NMR analysis showing that glycolytic rate measured from conversion of $\left[1-{ }^{13} \mathrm{C}\right]$ glucose into $\left[3-{ }^{13} \mathrm{C}\right]$ lactate is not changed upon $\alpha$-TOA treatment (data not presented).

$\alpha$-TOA induces a moderate increase in mitochondrial ROS activity

As detected on the basis of a flow-cytometry analysis of the cells (MitoSOX), the $\alpha$-TOA treatment results in a moderate but consistent enhancement of mitochondrial ROS activity (Figure 6). This range of ROS enhancement is typically related to their regulatory role [22].

$\alpha$-TOA-induced inhibition of the electron flux does not exhibit a major impact on the mitochondrial inner membrane potential

Based on the measure of mitochondrial inner membrane potential by flow-cytometry in the cells treated by TMRM, a mitochondria depolarization detector, the $\alpha$-TOA does not significantly impact this parameter, although some trend of decrease has been detected, which is similar to the effect of 
a physiologically relevant low $\mathrm{O}_{2}$ concentration (3\%O2) (Figure S2). The similar absence of impact is detected on the level of mitochondrial mass (MitoTracker green staining), which is not impacted by $\alpha$-TOA (at the active dose of $10 \mu \mathrm{M}$ tested) (Figure S2).

$\alpha$-TOA induces stabilization of HIF1- $\alpha$

Typically, the HIF1- $\alpha$ protein is degraded in cells cultured at $20 \% \mathrm{O}_{2}$, while in culture at $3 \% \mathrm{O}_{2}$ or in presence of chemical agents such as $\mathrm{CoCl}_{2}$, its degradation is decreased, which permits accumulation of this protein in the cell. (Figure 7). In all doses tested, the $\alpha$-TOA resulted in a stabilization of HIF1$\alpha$ in cells cultured at $20 \% \mathrm{O}_{2}$ after 72 hours of expansion. However, the different pattern of the bands among $\alpha$-TOA treated and low oxygen expanded controls could suggest a distinct pattern of HIF-1 $\alpha$ posttranslational modifications (Figure 7).

Induced Vitamin E inadequacy in mice results in the depletion of mesenchymal stem cells in progenitor cells in bone marrow

The food containing Vitamin $E$ in our experiments ensures the $\alpha$-TOA levels $(8.82 \pm 1.9 \mu \mathrm{M}$ and $7.41 \pm 1.97 \mu \mathrm{M}$ after 2 and 5 months, respectively (not shown)) which correspond to those described for mice in physiological conditions and exposed to a standard diet (cited in [23]). Vitamin Edeprived food regime results in a decrease in $\alpha$-TOA levels $(3.8 \pm 0.23 \mu \mathrm{M}$ and $<3.22 \mu \mathrm{M}$ after 2 and 5 months, respectively (not shown), while the addition of Vitamin E after 2 months of Vitamin-Edeprived food diet resolved the relative $\alpha$-TOA inadequacy $(7.28 \pm 1.84 \mu \mathrm{M}$ after 5 months (not shown)). This $\alpha$-TOA inadequacy resulted in a significant ( $\sim 5$ fold) decrease in femoral CFU-F content with respect to the mice exhibiting normal $\alpha$-TOA levels ("Deficient" vs. "Controls", Figure 8). The CFU-F femoral content is completely normalized if $\alpha$-TOA is introduced after 2 months of Vitamin $E$ deprived diet for a further 3 months, clearly proving that the phenomenon is $\alpha$-TOA-dependent ("Deficient" vs. "Deficient-resolved" Figure 8). 


\section{Discussion}

The results presented here represent the first demonstration that $\alpha$-TOA has a positive impact on the maintenance of mesenchymal stem and progenitor cell proliferative capacity and suggest the role of $\alpha-\mathrm{TOH}$ in the physiological maintenance of primitive cells in vivo. Our results suggest that the lower doses of $\alpha$-TOA act at the level of the maintain of stemness while the higher doses, reaching the limit of physiological range as well as the supra-physiological ones, affect the commitment of MSC. While the ex-vivo data can always be relativized, the in vivo results presented here argue in favor of a consistent effect of Vitamin E on the maintaining of the proliferative capacity of stromal cells in an appropriate (physiological) environment. Also, the data presented in this paper argues that this effect is not related to an anti-oxidant function of $\alpha$-TOA. It is interesting to note that the most recent data points to reduction of replicative senescence of human skin fibroblasts by $\alpha$ tocopherol via reduction of senescence-associated beta-galactosidase [24].

Our cultures were performed in standard conditions i.e. exposed to $20 \% \mathrm{O}_{2}$ concentration, which is a supra-physiological oxygen concentration, several fold higher than physiological ones $\left(1-3 \% \mathrm{O}_{2}\right)$. In fact, the results of an ongoing project in our laboratory revealed that a culture similar to ones explored here contains $\sim 180 \mu \mathrm{M}$ of dissolved $\mathrm{O}_{2}$ while the cultures exposed to $3 \%$ and $1 \% \mathrm{O}_{2}$ contained $\sim 27$ and $\sim 14 \mu \mathrm{M} \mathrm{O}_{2}$ (non-published data), respectively, which are physiologically relevant concentrations for stromal niches of bone marrow $[25,26]$. Similar positive effects as were detected with $\alpha$-TOA on the maintenance of proliferative capacity of MSC and MPC was obtained if cultures were exposed to these physiologically relevant oxygen concentrations. With that in mind, one might consider that $\alpha$-TOA exhibits some low oxygen concentration-mimicking effect. Indeed, when the OCR of the hBM MStroC cultured in presence of different doses of $\alpha$-TOA was measured, it turned out to be reduced. This reduction is most probably due to the attenuation of respiratory chain electron flow, at the level of complex II. This seems not be in line with the data of Dos Santos, who 
showed in vitro that the complex I exhibited a higher affinity for $\alpha$-tocopheryl-succinate ( $\alpha$-TOS) than the complex II [27]. However, the data ex vivo, suggesting $\alpha$-TOS action via complex II were also presented [28]. These results show that the inactivation of succinate dehydrogenase (SDH) (complex II) ex vivo abolishes $\alpha$-TOS inhibition of ETC, whereas inactivation of complex I was ineffective (though, our results also suggest that the complex I was not inhibited upon $\alpha$-TOA treatment). Furthermore, employing biochemical, molecular genetics and in silico modeling they provided strong arguments that the complex II is the main site of $\alpha$-TOS inhibition of ETC: $\alpha$-TOS could displace CoQ from complex II, interacting with both their QP and QD binding pockets [28]. Naturally occurring $\alpha$ tocopherol has been also reported to interact with a CoQ binding site on complex II [29]. $\alpha$ Tocopherol and two tocopherol esters, $\alpha-$ TOS and $\alpha-$ TOA, are related in molecular structure and number of rotational bounds [30], indicating that the complex II inhibition we observed could employ this mechanism. In addition, we provide here data that could support the scenario that $\alpha$ TOA acts probably as an inhibitor of ETC rather than an uncoupling agent. Similar conclusions can be derived from the observations that $\alpha$-TOS can reduce mitochondrial respiration in course of a high energy demand, without causing ineffective oxygen consumption in the state IV of respiration [27].

The action of $\alpha$-TOS on ETC is extensively studied in the context of its use as a potent anti-cancer drug, since it was observed that it can induce selective growth inhibition and apoptosis in cancer cells unlike in normal non-transformed cells [27-29,31-33]. The major path of $\alpha$-TOS cytotoxicity in cancer cells has been suggested to relay on rapid proton motor force (PMF) i.e. inner mitochondrial membrane potential (IMMP) collapse and vast mtROS increase [27,28,34]. The comparison of $\alpha$-TOS effects in leukemic and normal mice cells, suggests that in normal cells the amplitude of mtROS increase could be limited and insufficient to support apoptosis initiation [27] although probably sufficient for a regulatory actions [35]. In hBM MStroC exposed to $\alpha$-TOA neither apoptosis nor PMF depletion is observed, although a moderate mtROS augmentation has been detected. Moreover, IMMP of the cells cultured at $20 \% \mathrm{O}_{2}$ and treated with the $\alpha$-TOA exhibited the same trend as in cultures expanded at $3 \% \mathrm{O}_{2}$ compared to one propagated at atmospheric oxygenation. Indeed, the 
modest mtROS augmentation is involved in the signal transduction, and exhibits a central role in the cell response to low oxygen [4,35-39]. Paradoxically, low oxygen environment may evoke low mtROS increase by interfering with electron flow through the ETC. This way, prosthetic groups of ETC enzymes can reach a redox status enabling a direct transfer of electron to molecular oxygen [35,3839]. The most prominent cascade modulated by low oxygen-induced mtROS is the turnover of hypoxia-inducible factor $\alpha$ subunits, including HIF-1 $\alpha[35,37-38,40]$. In all likelihood, the mtROS increase we found in hBM MStroC exposed to $\alpha$-TOA, although the cultures were performed at $20 \%$ $\mathrm{O}_{2}$, could be considered to exert the same mechanism of PHD regulation. In other words, the $\alpha$-TOAinduced ROS increase might stabilize HIFs which is in line with our results. However, Guzy and Schumacker stressed the complex III of ETC as the main source of mtROS that regulates HIF- $\alpha$ degradation [38]. Even if we do not present the data concerning the $\alpha$-TOA action on complex III, the fact that the attenuated electron flow through the complex II was evidenced does not implicate that the complex II is the only source of ETC mtROS. The prosthetic groups proximal or distal to complex II engaging the carriers embedded at complex I and complex III could be affected by the complex II quenching, which could elicit mtROS as well [35]. Nonetheless, the considerations of $\alpha$-TOA-induced mtROS sources (complexes) in ETC, evoked in this discussion, and its implication in HIF-1 $1 \alpha$ subunit turnover remain to be further elucidated. Furthermore, the inhibition of complex II could enhance succinate and/or fumarate levels in the cell [41-43]. These Krebs's cycle intermediators have been demonstrated to bind with a high affinity for $\alpha$-ketoglutarate pocket at PHD, acting as a potent inhibitor of its catalytic action, suggesting an additional mechanism for $\alpha$-TOA-mediated HIF-1 $\alpha$ induction in hBM MStroC $[8,43-44]$.

The HIF regulation by mtROS might suggest some responses to the question of the maintenance of primitiveness of MSC and MPC by $\alpha$-TOA. HIF family is a principal gene expression regulator in anaerobiosis and microaerophilia [45-47]. This metabolic set-up is not exclusively implicated in cell survival and homeostasis under low oxygen, but it is also important in the mechanism of primitive cells self-renewal regulation [7,25,48-49]. Additionally, studies on hBM MStroC exposed to 
physiological (low) oxygenation revealed HIF-1 engagement in some so-called "stemness genes" regulation such as Oct-4 and KIf-4 indicating it is firmly embedded in MSC and MPC function [50-51]. However, the evaluation of glycolytic activity in hBM MStroC exposed to $\alpha$-TOA we performed did not reveal an increase, questioning the functionality of HIF-1 transcriptional factor under these conditions i.e. its impact on the maintenance of hBM MstroC proliferative capacity. HIF-1 $\alpha$ can indeed be present in the cells, but maintained silent via mechanism employing another Hydroxylase Factor Inhibiting HIF (FIH) $[38,46]$. FIH demands lower oxygen concentrations and it is insensible to the succinate and fumarate inhibition, allowing its function in the situation where the PHD is inhibited [42-43]. If the HIF-1 is inactive and the glycolytic shift out of consideration, how then can the maintenance of primitiveness by $\alpha$-TOA can be explained? The possible response may be in a mtROS-driven mechanism, which has been suggested as a critical regulator of stem cell fate. These reports assume the physiological mtROS concentration in the micro- environmental low $\mathrm{O}_{2}$ as being crucial for the maintenance of stemness while the enhancement of mtROS over this niche-relevant level leads to the commitment and differentiation [52-55]. In fact, this physiological mtROS level corresponds to the "steady state" in situ mtROS levels as ones found at physiologically relevant $\mathrm{O}_{2}$ concentrations $[22,35,38]$. We believe that the mtROS enhancement obtained upon $\alpha$-TOA treatment could rather be considered to be under the threshold of inducing differentiation. This minimal critical level of mtROS is also indispensable for pluripotent stem cells (iPSC) since induction is prevented if the mtROS are strongly suppressed [54].

Thus, our results are in line with the general idea that an appropriate mtROS level seems to be a conditio sine qua non for the maintenance of stemness. It remains to elucidate the mechanism of this action, which stemness genes could be regulated in mtROS-dependent mechanism and how. However, our results do not support the scenario of HIF-1 transcriptional factor as a major player.

Whatever the mechanism underlying these effects on mesenchymal stem and progenitor cells, the results presented here suggest that $\alpha$-TOA can have a role in MSC maintenance. If the active 
principle of $\alpha$-TOA is $\alpha$-TO, the standard $\alpha$-TO-deprived culture is rather a model of Vitamin $E$ deficiency, the $\alpha$-TOA treated culture represents the re-establishing of a physiological state. If so, then, $\alpha$-TO deficiency (and even inadequacy) in vivo might compromise the maintenance of MSC pool i.e. provoke MSC exhaustion and decrease of the bone marrow stock of these cells. And this is exactly what the results of our in vivo mice experiments corroborated.

\section{Conclusions}

The $\alpha$-TOA capacity to induce, in standard culture conditions $\left(20 \% \mathrm{O}_{2}\right)$, some of the most prominent cascades operative at low oxygen, firmly encourages its future consideration as a factor that can mimic hypoxia. Notably important are observed effects on hBM MStroC functional properties, that could be, at least in part, assigned to mtROS signaling. Though, a possible involvement of other paths or direct $\alpha$-TOA engagement in gene expression induction remains to be elucidated. Moreover, possible $\alpha$-TOA enrolment in a decrease of HIF-1 $\alpha$ protein degradation might result in an effective HIF-1 transcriptional heterodimer if associated with other factors such as a low $\mathrm{O}_{2}$ concentration. Additionally, hypoxia mimetic properties and the absence of apoptosis make $\alpha$-TOA attractive for clinical grade hBM MStroC ex vivo manipulation in an effort to ameliorate their initial survival and retention after administration into ischemic tissue.

Acknowledgments: We would like to thank Mrs Elisabeth Doutreloux-Volkmann for preliminary English reading and Ms Nyere Gibson for the definitive proof-reading.

Availability of Data and Materials Most data generated or analyzed during the study are included in published article and its supplementary files. Some row data are available from authors upon a reasonable request.

Authors contributions: DL: collection and assembly of data, statistical analysis, manuscript writing. LR: Collection and assembly of data, statistical analysis. CD, NC, VL, AV: collection and assembly of 
data. A-K B-S, PBG, MV-L, SP: collection, analysis and synthesis if data, manuscript reading. ZI: conception of the project, experimental design, collection data supervising, analysis and synthesis of results, manuscript writing, manuscript revision and submitting.

Funding information: This project was supported by the A.E.C.T Euro region Aquitania-EuskadiNavarra (2019/3) grant "Cardioreg", annual research budget of EFS-NVAQ and III41004 MESTD RS of Ministry of Education, Science and Technological Development, Republic of Serbia.

\section{Compliance with ethical standards}

Conflict of interest: The authors declare that they have no conflict of interestany conflict of interest.

Ethics Approval. Human cells and animal experiments were involved in this study. The use of the cells for the purpose of scientific research in our laboratory was approved by Ministry of Education and Research of French Republic in compliance with regulatory procedures that apply (DC 20131998, DC 2018-3143 and DC 2019-3713). Concerning the animal studies, upon a favorable opinion of the Bordeaux Ethics Committee for animal experimentation, this project was authorized by the French National Ministry of the High Education and Research (APAFIS\#134682018020914295792v4).

Informed consent. The informed consent for the experimental use of bone marrow cells destined to be discarded was obtained systematically in context of the file for abovementioned approval of Ministry of Education and Research

\section{References}

1. Caplan, A. I. (2017). Mesenchymal Stem Cells: Time to Change the Name! Stem Cells TransI Med, 6(6), 1445-1451. doi:10.1002/sctm.17-0051

2. Loncaric, D., Labat, V., Debeissat, C., Brunet de la Grange, P., Rodriguez, L., Vlaski-Lafarge, M., \& Ivanovic, Z. (2018). The majority of cells in so-called "mesenchymal stem cell" population are neither stem cells nor progenitors. Transfus Clin Biol. doi:10.1016/j.tracli.2018.08.157 
3. Copland, I. B. (2011). Mesenchymal stromal cells for cardiovascular disease. J Cardiovasc Dis Res, 2(1), 3-13. doi:10.4103/0975-3583.78581

4. Li, L., Chen, X., Wang, W. E., \& Zeng, C. (2016). How to Improve the Survival of Transplanted Mesenchymal Stem Cell in Ischemic Heart? Stem Cells Int, 2016, 9682757. doi:10.1155/2016/9682757

5. Sandvig, I., Gadjanski, I., Vlaski-Lafarge, M., Buzanska, L., Loncaric, D., Sarnowska, A., . . . Ivanovic, Z. (2017). Strategies to Enhance Implantation and Survival of Stem Cells After Their Injection in Ischemic Neural Tissue. Stem Cells Dev, 26(8), 554-565. doi:10.1089/scd.2016.0268

6. Beegle, J., Lakatos, K., Kalomoiris, S., Stewart, H., Isseroff, R. R., Nolta, J. A., \& Fierro, F. A. (2015). Hypoxic preconditioning of mesenchymal stromal cells induces metabolic changes, enhances survival, and promotes cell retention in vivo. Stem Cells, 33(6), 1818-1828. doi:10.1002/stem.1976

7. Ivanovic, Z. (2013). Respect the anaerobic nature of stem cells to exploit their potential in regenerative medicine. Regen Med, 8(6), 677-680. doi:10.2217/rme.13.65

8. Ivanovic, Z. (2017). Stem cell evolutionary paradigm and cell engineering. Transfus Clin Biol, 24(3), 251-255. doi:10.1016/j.tracli.2017.05.004

9. Schneider, C. (2005). Chemistry and biology of vitamin E. Mol Nutr Food Res, 49(1), 7-30. doi:10.1002/mnfr.200400049

10. Ivanovic, Z., Chevaleyre, J-A, Rodriguez, L., Attebi, E. (2016). Milieu de conservation injectable pour la conservation de cellules du sang placentaire de la moelle osseuse et du sang périphérique. French patent PCT/FR2016/052253.

11. Rodriguez, L., Brunet de la Grange, P., Loncaric, D., Duchez, P., Chevaleyre, J., Ivanovic, Z. (2016). L'Alpha tocophérol maintien l'état primitif des cellules CD34+ de sang placentaire. Trans Clin Biol, 24 ( $\left.\mathrm{N}^{\circ} 3 \mathrm{~S}\right), 376$.

12. Dominici, M., Le Blanc, K., Mueller, I., Slaper-C21ortenbach, I., Marini, F., Krause, D., Deans, R., Keating, A., Prockop, D.J., Horwitz, E. (2006). Minimal criteria for defining multipotent mesenchymal stromal cells. The International Society for Cellular Therapy position statement. Cytotherapy. 8(4):315-7. doi: 10.1080/14653240600855905.

13. Faure, H., Preziosi, P., Roussel, A-M., Bertrais, S., Galan, P., Hercberg, S., Favier A. (2006). Factors influencing blood concentration of retinol, alpha-tocopherol, vitamin $\mathrm{C}$, and betacarotene in the French participants of the SU.VI.MAX trial. Eur J Clin Nutr, 60(6):706-717. doi: 10.1038/sj.ejcn.1602372.

14. Ford, E.S., Schleicher, R.L., Mokdad, A.H., Ajani U.A., Liu, S. (2006). Distribution of serum concentrations of alpha-tocopherol and gamma-tocopherol in the US population Am J Clin Nutr, . 84(2):375-383. doi: 10.1093/ajcn/84.1.375.

15. Cuerq, C., Restier, L., Drai, J., Blond, E., Roux, A., Charriere, S., Michalski, M.C., Di Filippo, M., Levy, E., Lachaux, A. (2016). Peretti N. Establishment of reference values of $\alpha$-tocopherol in plasma, red blood cells and adipose tissue in healthy children to improve the management of chylomicron retention disease, a rare genetic hypocholesterolemia. Orphanet J Rare Dis, 11(1):114. doi: 10.1186/s13023-016-0498-8.

16. Qian, W., Van Houten, B. (2010). Alterations in bioenergetics due to changes in mitochondrial DNA copy number. Methods. 51(4):452-7. doi: 10.1016/j.ymeth.2010.03.006.

17. Symersky, J., Osowski, D., Walters, D.E., Mueller, D.M. (2012). Oligomycin frames a common drug-binding site in the ATP synthase. Proc Natl Acad Sci U S A. 109(35):13961-5. doi: $10.1073 /$ pnas.

18. Pinchot GB. (1967). The mechanism of uncoupling of oxidative phosphorylation by 2,4dinitrophenol. J Biol Chem. 242(20):4577-83. 
19. Heinz, S., Freyberger, A., Lawrenz, B., Schladt, L., Schmuck, G., Ellinger-Ziegelbauer, H. (2017).

Mechanistic Investigations of the Mitochondrial Complex I Inhibitor Rotenone in the Context of Pharmacological and Safety Evaluation. Sci Rep. 7:45465. doi: 10.1038/srep45465.

20. Ma, X., Jin, M., Cai, Y., Xia, H., Long, K., Liu, J., Yu, Q., Yuan, J. (2011). Mitochondrial electron transport chain complex III is required for antimycin A to inhibit autophagy. Chem Biol. 18(11):1474-81. doi: 10.1016/j.chembiol.2011.08.009.

21. Salabei, J.K., Gibb, A.A., Hill, B.G. (2014). Comprehensive measurement of respiratory activity in permeabilized cells using extracellular flux analysis. Nat Protoc. 9(2):421-38. doi: 10.1038/nprot.2014.018.

22. Li, X., Fang, P., Mai, J., Choi, E. T., Wang, H., \& Yang, X. F. (2013). Targeting mitochondrial reactive oxygen species as novel therapy for inflammatory diseases and cancers. J Hematol Oncol, 6, 19. doi:10.1186/1756-8722-6-19

23. Baxter, L.L., Marugan, J.J., Xiao, J., Incao, A., McKew, J.C., Zheng, W., Pavan, W.J. (2012). Plasma and tissue concentrations of $\alpha$-tocopherol and $\delta$-tocopherol following high dose dietary supplementation in mice. Nutrients, 4:467-90. doi: 10.3390/nu4060467. Epub 2012 Jun 6.

24. Ricciarelli, R., Azzi, A., Zingg, J.M. (2020). Reduction of senescence-associated betagalactosidase activity by vitamin $\mathrm{E}$ in human fibroblasts depends on subjects' age and cell passage number. Biofactors. doi: 10.1002/biof.1636.

25. Ivanovic, Z., Vlaski-Lafarge, M. (2015). Anaerobiosis and Stemness: An Evolutionary Paradigm for Therapeutic Applications. Academic pres Elsevier.

26. Spencer, J. A., Ferraro, F., Roussakis, E., Klein, A., Wu, J., Runnels, J. M., . . Lin, C. P. (2014). Direct measurement of local oxygen concentration in the bone marrow of live animals. Nature, 508(7495), 269-273. doi:10.1038/nature13034

27. dos Santos, G. A., Abreu e Lima, R. S., Pestana, C. R., Lima, A. S., Scheucher, P. S., Thome, C. H., . . . Rego, E. M. (2012). (+)alpha-Tocopheryl succinate inhibits the mitochondrial respiratory chain complex $I$ and is as effective as arsenic trioxide or ATRA against acute promyelocytic leukemia in vivo. Leukemia, 26(3), 451-460. doi:10.1038/leu.2011.216

28. Dong, L. F., Low, P., Dyason, J. C., Wang, X. F., Prochazka, L., Witting, P. K., . . N Neuzil, J. (2008). Alpha-tocopheryl succinate induces apoptosis by targeting ubiquinone-binding sites in mitochondrial respiratory complex II. Oncogene, 27(31), 4324-4335. doi:10.1038/onc.2008.69

29. Yu, L., \& Yu, C. A. (1983). Inhibitory effect of alpha-tocopherol and its derivatives on bovine heart succinate-cytochrome c reductase. Biochim Biophys Acta, 723(2), 139-149. doi:10.1016/0005-2728(83)90113-5

30. Azzi, A., \& Stocker, A. (2000). Vitamin E: non-antioxidant roles. Prog Lipid Res, 39(3), 231255.

31. Neuzil, J., Tomasetti, M., Zhao, Y., Dong, L. F., Birringer, M., Wang, X. F., . . Ralph, S. J. (2007). Vitamin $E$ analogs, a novel group of "mitocans," as anticancer agents: the importance of being redox-silent. Mol Pharmacol, 71(5), 1185-1199. doi:10.1124/mol.106.030122

32. Wang, X. F., Witting, P. K., Salvatore, B. A., \& Neuzil, J. (2005). Vitamin E analogs trigger apoptosis in HER2/erbB2-overexpressing breast cancer cells by signaling via the mitochondrial pathway. Biochem Biophys Res Commun, 326(2), 282-289. doi:10.1016/j.bbrc.2004.11.028

33. Weber, T., Dalen, H., Andera, L., Negre-Salvayre, A., Auge, N., Sticha, M., . . Neuzil, J. (2003). Mitochondria play a central role in apoptosis induced by alpha-tocopheryl succinate, an agent with antineoplastic activity: comparison with receptor-mediated pro-apoptotic signaling. Biochemistry, 42(14), 4277-4291. doi:10.1021/bi020527j 
34. Yamamoto, S., Tamai, H., Ishisaka, R., Kanno, T., Arita, K., Kobuchi, H., \& Utsumi, K. (2000). Mechanism of alpha-tocopheryl succinate-induced apoptosis of promyelocytic leukemia cells. Free Radic Res, 33(4), 407-418.

35. Murphy, M. P. (2009). How mitochondria produce reactive oxygen species. Biochem J, 417(1), 1-13. doi:10.1042/BJ20081386

36. Buravkova, L. B., Andreeva, E. R., Gogvadze, V., \& Zhivotovsky, B. (2014). Mesenchymal stem cells and hypoxia: where are we? Mitochondrion, 19 Pt A, 105-112. doi:10.1016/j.mito.2014.07.005

37. Guzy, R. D., Hoyos, B., Robin, E., Chen, H., Liu, L., Mansfield, K. D., . . Schumacker, P. T. (2005). Mitochondrial complex III is required for hypoxia-induced ROS production and cellular oxygen sensing. Cell Metab, 1(6), 401-408. doi:10.1016/j.cmet.2005.05.001

38. Guzy, R. D., \& Schumacker, P. T. (2006). Oxygen sensing by mitochondria at complex III: the paradox of increased reactive oxygen species during hypoxia. Exp Physiol, 91(5), 807-819. doi:10.1113/expphysiol.2006.033506

39. Semenza, G. L. (2007). Oxygen-dependent regulation of mitochondrial respiration by hypoxia-inducible factor 1. Biochem J, 405(1), 1-9. doi:10.1042/BJ20070389

40. Bell, E. L., Klimova, T. A., Eisenbart, J., Moraes, C. T., Murphy, M. P., Budinger, G. R., \& Chandel, N. S. (2007). The Qo site of the mitochondrial complex III is required for the transduction of hypoxic signaling via reactive oxygen species production. J Cell Biol, 177(6), 1029-1036. doi:10.1083/jcb.200609074

41. Hewitson, K. S., Lienard, B. M., McDonough, M. A., Clifton, I. J., Butler, D., Soares, A. S., . . Schofield, C. J. (2007). Structural and mechanistic studies on the inhibition of the hypoxiainducible transcription factor hydroxylases by tricarboxylic acid cycle intermediates. J Biol Chem, 282(5), 3293-3301. doi:10.1074/jbc.M608337200

42. Isaacs, J. S., Jung, Y. J., Mole, D. R., Lee, S., Torres-Cabala, C., Chung, Y. L., . . Neckers, L. (2005). HIF overexpression correlates with biallelic loss of fumarate hydratase in renal cancer: novel role of fumarate in regulation of HIF stability. Cancer Cell, 8(2), 143-153. doi:10.1016/j.ccr.2005.06.017

43. Selak, M. A., Armour, S. M., MacKenzie, E. D., Boulahbel, H., Watson, D. G., Mansfield, K. D., . . . Gottlieb, E. (2005). Succinate links TCA cycle dysfunction to oncogenesis by inhibiting HIFalpha prolyl hydroxylase. Cancer Cell, 7(1), 77-85. doi:10.1016/j.ccr.2004.11.022

44. Koivunen, P., Hirsila, M., Remes, A. M., Hassinen, I. E., Kivirikko, K. I., \& Myllyharju, J. (2007). Inhibition of hypoxia-inducible factor (HIF) hydroxylases by citric acid cycle intermediates: possible links between cell metabolism and stabilization of HIF. J Biol Chem, 282(7), 45244532. doi:10.1074/jbc.M610415200

45. Dengler, V. L., Galbraith, M., \& Espinosa, J. M. (2014). Transcriptional regulation by hypoxia inducible factors. Crit Rev Biochem Mol Biol, 49(1), 1-15. doi:10.3109/10409238.2013.838205

46. Kaelin, W. G., Jr., \& Ratcliffe, P. J. (2008). Oxygen sensing by metazoans: the central role of the HIF hydroxylase pathway. Mol Cell, 30(4), 393-402. doi:10.1016/j.molcel.2008.04.009

47. Majmundar, A. J., Wong, W. J., \& Simon, M. C. (2010). Hypoxia-inducible factors and the response to hypoxic stress. Mol Cell, 40(2), 294-309. doi:10.1016/j.molcel.2010.09.022

48. Hsu, S. H., Chen, C. T., \& Wei, Y. H. (2013). Inhibitory effects of hypoxia on metabolic switch and osteogenic differentiation of human mesenchymal stem cells. Stem Cells, 31(12), 27792788. doi:10.1002/stem.1441

49. Ivanovic, Z. (2009). Hypoxia or in situ normoxia: The stem cell paradigm. J Cell Physiol, 219(2), 271-275. doi:10.1002/jcp.21690

50. Covello, K. L., Kehler, J., Yu, H., Gordan, J. D., Arsham, A. M., Hu, C. J., . . Keith, B. (2006). HIF-2alpha regulates Oct-4: effects of hypoxia on stem cell function, embryonic development, and tumor growth. Genes Dev, 20(5), 557-570. doi:10.1101/gad.1399906 
51. Park, I. H., Kim, K. H., Choi, H. K., Shim, J. S., Whang, S. Y., Hahn, S. J., . . . Oh, I. H. (2013). Constitutive stabilization of hypoxia-inducible factor alpha selectively promotes the selfrenewal of mesenchymal progenitors and maintains mesenchymal stromal cells in an undifferentiated state. Exp Mol Med, 45, e44. doi:10.1038/emm.2013.87

52. Bigarella, C. L., Liang, R., \& Ghaffari, S. (2014). Stem cells and the impact of ROS signaling. Development, 141(22), 4206-4218. doi:10.1242/dev.107086

53. Hu, R., Li, H., Liu, W., Yang, L., Tan, Y. F., \& Luo, X. H. (2010). Targeting miRNAs in osteoblast differentiation and bone formation. Expert Opin Ther Targets, 14(10), 1109-1120. doi:10.1517/14728222.2010.512916

54. Lee, J., Cho, Y. S., Jung, H., \& Choi, I. (2018). Pharmacological Regulation of Oxidative Stress in Stem Cells. Oxid Med Cell Longev, 2018, 4081890. doi:10.1155/2018/4081890

55. Vlaski-Lafarge, M., \& Ivanovic, Z. (2015). Reliability of ROS and RNS detection in hematopoietic stem cells--potential issues with probes and target cell population. J Cell Sci, 128(21), 3849-3860. doi:10.1242/jcs.1714 


\section{Figure Legends:}

Figure 1. $\alpha$-TOA does not impact either hBM MStroC proliferation kinetics or their progress through the cell cycle. A. Proliferation kinetics hBM MStroC. Means+SE of three independent experiments performed with the samples of 3 different donors : $\alpha$-TOA treated vs non-treated cells, evaluated by Trypan Blue discrimination test during the 5 day-culture. B. The plots represent cell cycle phase distribution (Ki67/PI) of the hBM MStroC in presence or absence $(0 \mu \mathrm{M}-150 \mu \mathrm{M})$ of $\alpha-\mathrm{TOA}$. The discrimination was conducted on the basis of combined labelling use of anti-Ki67-Alexa 647 antibody and $\mathrm{PI}$ and the fluorescence was detected by flow cytometry $(n=3)$.

Figure 2. $\alpha$-TOA effects on hBM MStroC proliferative capacity. A. The histogram represents the percentage of hBM MStroC treated with $\alpha$-TOA (for $72 \mathrm{~h}, 10-150 \mu \mathrm{M}$ ) compared to the control which were capable of giving primary colonies subsequent to 14 days expansion in standard cell culture conditions. B. The percentage of 9-randomly selected primary colonies able to raise secondary colonies upon 14 days of culture. C. Relative amplification of the MStroC able to generate the colonies in secondary cultures with respect to control cultures $(0 \mu \mathrm{M} \alpha-\mathrm{TOA})$. D. The average percentage of individual cells form 9 randomly chosen primary colonies which were able to rise a secondary colony after 14 days $(n=1)$. The scheme illustrates the experimental strategy applied to obtain hBM MStroC proliferative capacity. E. Impact of $\alpha$-TOA on hBM MStroC multipotency. The proportion of tri-, bi- and uni-potent hBM MStroC in the populations exposed to 0 and $10-150 \mu \mathrm{M}$ of $\alpha-$ TOA for $72 \mathrm{~h}$. The demonstrated results are obtained by evaluating the capacity of the cells from primary cultures (i.e. derived from single-cell) to differentiate into osteocytes, chondrocytes and adipocytes $(n=1)$. 
Figure 3. $\alpha-$ TOA decreases parameters of mitochondrial activity in hBM MStroC. Mitochondrial oxygen consumption rate (OCR) was determined by using XF 24 flux analyzer in a MitoStress test (see material and methods) in hBM MStroC exposed to $10-150 \mu \mathrm{M}$ of $\alpha$-TOA for $24 \mathrm{~h}$ in standard cell culture conditions and compared to non-treated, control group of the cells $(n=4)$. A. Overall view of ETC activity and OXPHOS (one representative experiment). The histograms represent calculated parameters of mitochondrial activity: B. Basal rate of cellular respiration; C. Mitochondrial oxygen consumption; D. Non-mitochondrial oxygen consumption; E. Maximal respiratory capacity; F. Spare capacity and G. Proton leak. All values are expressed as OCR per 50000 cells in $\mathrm{pMol} / \mathrm{min}$. The statistical analyzes were performed using non-parametric Mann-Whitney $U$ test and only $p<0.05$ were considered as statistically significant.

Figure 4. $\alpha$-TOA could be considered as an inhibitor of complex II of ETC, but not as an uncoupling agent. The activity of individual complex I, II and IV have been determined in independent experiments in hBM MStroC exposed for $24 \mathrm{~h}$ to $10-150 \mu \mathrm{M}$ of $\alpha-\mathrm{TOA}$ and compared to the controls (the data presented at histograms $\mathrm{ABC}, \mathrm{DEF}$, and $\mathrm{GHI}$, for complex I, II and IV respectively). The measurements were performed using XF SeaHorse flux analyzer to detect OCR (pM/min) in the experimentally defined conditions for each individual complex of state III respiration - equivalent to ETC physiological activity in high demand for the energy in the cell (low ATP: ADP ratio) and state IV of respiration - corresponding to physiological ETC mode when the cells are fully energized (high ATP:ADP ratio). The respiration control ratio, as a parameter of ETC and OXPHOS coupling, was expressed as a State III: State IV according to the OCRs obtained for each individual complex. The significance of the differences was tested by non-parametric Mann-Whitney $U$ test and only the values $p<0.05$ were accepted as statistically significant.

Figure 5. $\alpha$-TOA did not impact glycolysis in hBM MStroC. The extra cellular acidification rate (ECAR) was determined in GlycoStress (see material and methods) test using XF 24 flux analyzer in hBM MStroC exposed to $10-150 \mu \mathrm{M}$ of $\alpha$-TOA for $24 \mathrm{~h}$ and compared to the control group $(n=4)$. A. Overall 
glycolytic flux parameters (one representative experiment); B. Basal extracellular acidification rate; C. Glycolytic activity; D. Glycolytic capacity; E. Glycolytic reserve and F. Non-glycolytic acidification. These parameters were calculated from ECAR values normalized on 50000 cells and expressed in $\mathrm{pH} / \mathrm{min}$ except the glycolytic reserve (E) which is expressed as percentage of control. The significance of differences will be tested by the non-parametric Mann-Whitney U test.

Figure 6. Inhibition of ETC by $\alpha$-TOA induces a low mtROS level enhancement. The histograms represent mtROS level measured in hBM MStroC exposed to $10-150 \mu \mathrm{M}$ of $\alpha-\mathrm{TOA}$ for $24 \mathrm{~h}$ expressed in percentage of corresponding control condition ( $0 \mu \mathrm{M} \alpha-T O A)$. Mann-Whitney $U$ test, only $p$-values inferior to 0.05 were considered as statistically significant.

Figure 7. $\alpha$-TOA decreases HIF-1 $\alpha$ protein degradation in hBM MStroC. The expression of HIF-1 $\alpha$ protein was detected by immunoblotting in hBM MStroC non-treated $(0 \mu \mathrm{M})$ and treated with $10 \mu \mathrm{M}-150 \mu \mathrm{M}$ of $\alpha-\mathrm{TOA}$ for $72 \mathrm{~h}$ at $20 \%$ O2. Protein extracts obtained from hBM MStroC incubated at $3 \% \mathrm{O} 2$ for $24 \mathrm{~h}$ and $72 \mathrm{~h}$ in cell culture medium and protein extracts obtained from hBM MStroC incubated for $24 \mathrm{~h}$ or $72 \mathrm{~h}$ at $20 \% \mathrm{O} 2$ and $3 \% \mathrm{O} 2$ supplemented by $100 \mu \mathrm{M}$ of $\mathrm{CoCl} 2$ in the last $6 \mathrm{~h}$ of expansion were used as positive controls. As negative controls were used protein extracts of hBM MStroC expanded at $20 \% \mathrm{O} 2$ in the cell culture medium for $24 \mathrm{~h}$ and $72 \mathrm{~h}$. The HIF- $1 \alpha$ specific bands were detected at $\sim 110 \mathrm{kDa}$ molecular weight. Anti- $\beta-$ Actin served as a protein loading control (band at approximately $40 \mathrm{kDa})$.

Figure 8. Total number of CFU-F per femur in mice 5 months after starting the a-tocopherol deficiency experiment. 